\title{
DESIGN AND ANALYSIS OF BODYWORKS OF A FORMULA STYLE RACECAR
}

\author{
Sagar B. Mishra ${ }^{1}$, Ali Asgar S. Khokhar ${ }^{2}$ \\ ${ }^{I}$ Graduate Student in Mechanical Engineering, Theem College of Engineering, Boisar, Maharashtra, India. \\ sagarm637@gmail.com \\ ${ }^{2}$ Graduate in Mechanical Engineering, KJ Somaiya College of Engineering, Mumbai, Maharashtra, India. \\ khokharali5252@gmail.com
}

\begin{abstract}
:
The aim was to develop a body of the racecar with the proper studies and analyses, taking into account several factors, to present an optimum structure as a final result. These factors include, but are not limited to, weight, cost, drag resistance, functionality and aesthetics. The expected product is to not just be appealing to the eye but also increase the performance of the vehicle. Additional objectives include being able to accommodate the budget while maintaining a highly competitive level to perform well in on the race track. The new design will reduce the weight of the prototype and as well as the air drag, taking into consideration the ground effects desired to be implemented in the vehicle as a crucial factor. Moreover, the new body will be easier to dismantle reducing the service time.
\end{abstract}

Keywords: drag resistance, aesthetics, performance, weight, cost.

\section{INTRODUCTION}

Aerodynamics plays a crucial part in the performance any race car. The aim of a racecar designer is to design a machine that can cross the finish line in the fastest lap time. Recent scenarios have shown the importance of aerodynamics on speeding vehicles.

Designers often give more importance to aerodynamics than to structural factors as it is observed that aerodynamics emerges to be the deciding factor between the winner and the loser, and thus is practiced extensively in the design phase. Our proposed design is going to involve creating sectional composite parts that will come together to create an exoskeleton that would cover $80 \%$ of the vehicle. This design will configure different aerodynamic packages that will add to main body and will be mounted on the chassis shown below. The parts of bodyworks considered for analysis are Nose Cone and side pods (explained later).

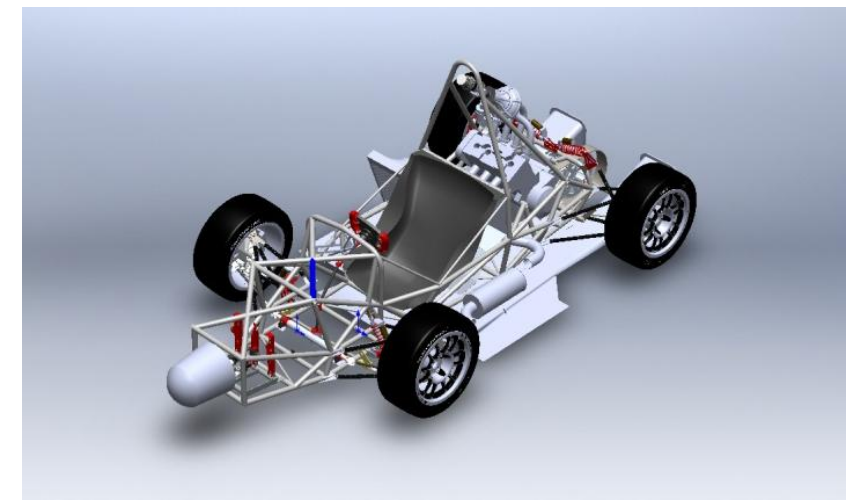

Figure2: Final Assembly of complete car on which bodyworks would be mounted.

\section{CONSIDERING ALTERNATE MATERIALS}

Following the same idea explained on the abstract of this section, our main goal is performance and aesthetics of the vehicle to increase the scores given by the competition judges. Therefore, as per our research there are three main types of materials used in teams all from around the world. Aluminum, Fiberglass and Carbon fiber; all of these materials have their pros and cons as per their properties and we didn't want to get too much into detail with these because it really depends on the team goals and ease of availability. Aluminum was almost immediately discarded, because of how hard it is to shape around an aerodynamic design. If we were to choose this material, we'll have to go with a more simple design with flat panels shaping the body. Fiberglass, Although it is much cheaper than carbon fiber, it is a heavier, harder to work, and even dangerous material due to its very explosive fracturing failure, it doesn't present the expected characteristics. Therefore, the material of choice will be carbon fiber due to its low density, durability, strength and aesthetics. The design also has to be pleasing to the eye since it will be judged in competition by a group of engineers world. For these reasons we decided to take the path of carbon fiber composite, rather than using fiberglass or even aluminum which will increase weight and compromise strength. The research has shown than unlike earlier days, the carbon fiber composite is much more affordable now, and the curing process is close to that of fiberglass.

\section{ENGINEERING DESIGN AND ANALYSIS}

The designing of the bodyworks was started with inputs from Chassis, Exhaust Routing and muffler position and the 
radiator position. Along with these inputs, flow over body work (Aerodynamics), manufacturing cost and feasibility and quick convenient assembly and disassembly were other major design considerations.

\section{Body Nose:}

When designing the body of a racecar, the two main purposes for the geometry of the body are to slice through air as efficient as possible and to channel desired locations to produce downforce. When we apply this force in specific locations of the car, we can increase grip on the tires, thus improving performance.

The Bernoulli Principle can further explain the previously mentioned force. As seen in racecar aerodynamics, this principle explains that a fluid flowing around an object can experience changes in pressure. This is due to the fact that a slowing down vehicle creates more pressure than a speeding one. By controlling the shape of the object, this change of pressure can force the body to a desired direction.

\section{A. Iteration 1:}

Here the Exoskeleton was divided in to 4 parts namelyNose, $2 *$ Side pods, Rear panel. The main advantage of this design was that number of parts to be manufactured was less. This design was comparatively complex as it involved various contours in it. Machining of the patters will also be costlier in this design.

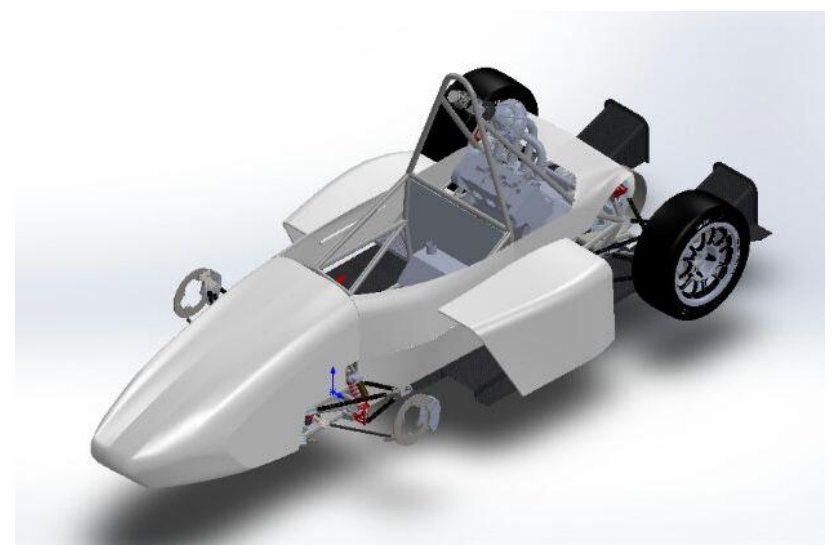

Figure 3: Bodywork Iteration 1 showing the nose and sidepod.

\section{Iteration 2:}

Here the Exoskeleton was divided in to 6 parts namely; Nose, $2 *$ Side panel, $2 *$ Side pods, Rear panel. The main advantage of this design is its simplicity. As we can see, having involved less contours, the design is easy to manufacture. Machining of the pattern is also cheaper in this case.

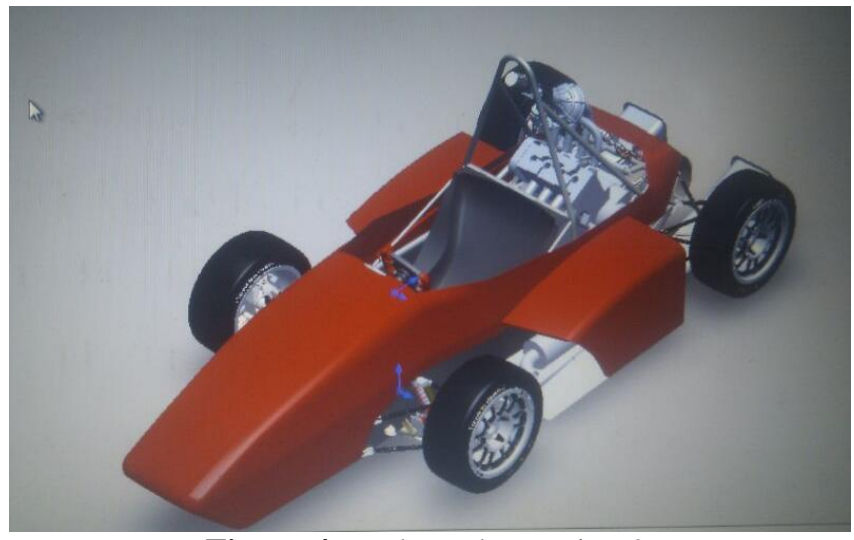

Figure 4: Bodywork Iteration 2

As shown, iteration 2 was selected, as it was more appealing as well is it was easier to manufacture. Thus it highlighted both the objective simplicity as well as aesthetic look. Being simple to manufacture it would be comparatively cheaper to manufacture the patterns and molds.

\section{B. Modeling:}

After the basic design was finalized it was modeled using Solidworks. The model was designed considering interferences with various system such as Suspension AArm location, Exhaust routing, Radiator location, etc. considering the mounting too. Driver egress was also considered while designing the bodyworks. It was made sure that the surfaces are continuous and smooth across the body so that the flow will be laminar. And thus, this is the initial iteration which was modeled.

\section{Aerodynamic Consideration in Design:}

The objective was to have a simple and lightweight aero package which could be simulated and tested with the available resources. Body works has been developed around the car with the objective of minimum drag. Being an initiation into aerodynamics our focus was more onto reducing the drag of the car rather than maximizing the down force. Solid Work Flow Express feature was used to enhance our design and make sure that our objectives are fulfilled.

\section{Modeling the Body Nose:}

Being the first part to interact with the air, its profile is very important to distribute the air across the vehicle. Initial profile modelled on the guidelines of aesthetics is having very sharp contours and abrupt change in profile which was then analysed via flow simulations. Thus the contours were smoothened and a balance between aesthetics as well as drag co-efficient was made.

Following shown are the iterations of the basic design which were modified to make the flow over the nose cone smooth and laminar. Also the simplicity of manufacturing was considered in addition to above criteria. 


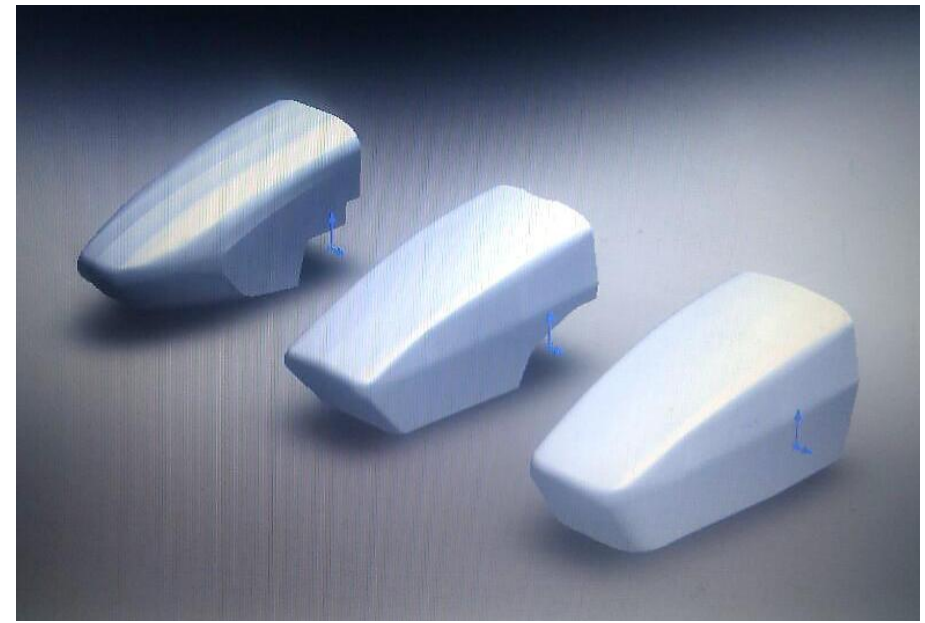

Figure 5: Nose Comparison (Isometric View) showing modifications

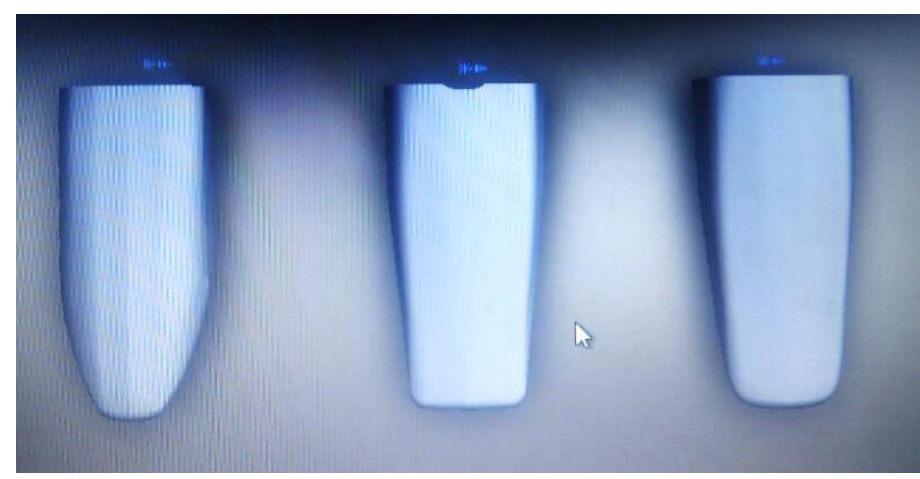

Figure 6: Nose Comparison (Top View)

\section{Sidepod:}

The air that passed through the nose is then guided to the side of splitter located just in front of the side pods. The design of side pod can smoothen out the airflow that has been disturbed by front wheels. It separates the flow into two parts; one is directed into the side pod and other is diverted outside. The air passes through the smooth surface of side pod with minimum drag force. It acts to block the airflow from hitting the rear wheels. The direct hit of air on the wheels may create turbulent which disturbs the whole airflow dynamics on the real part of car. The design makes the air steadier. Besides, the installation of side pods increases the safety of the car, it is able to stabilize the whole body of car and protects driver from side collisions. Air directed into the side pod is also used to cool the engine; it acts like a radiator essential to enhance the performance of engine and protect it from overheating.

The side pods were so designed that it would act as a duct for the radiator and improve cooling. Due to increase in its area across the length it will act as a diffuser thus reduces the velocity of air across the radiator. The area of inlet of the side pod is kept approx 0.7 times the radiator area as per the study from literature. The side pod is a L- section which is mounted on one end on side panel and other end resting on under tray. Thus the $\mathrm{L}$ - section with the under tray resembles a $\mathrm{C}$ - section with the bottom under tray as a flat plate.

The side pod were analysed with pressure and velocity plots for inlet velocity of $14 \& 18 \mathrm{~m} / \mathrm{s}$.

NOTE: More analysis is shown in further sections

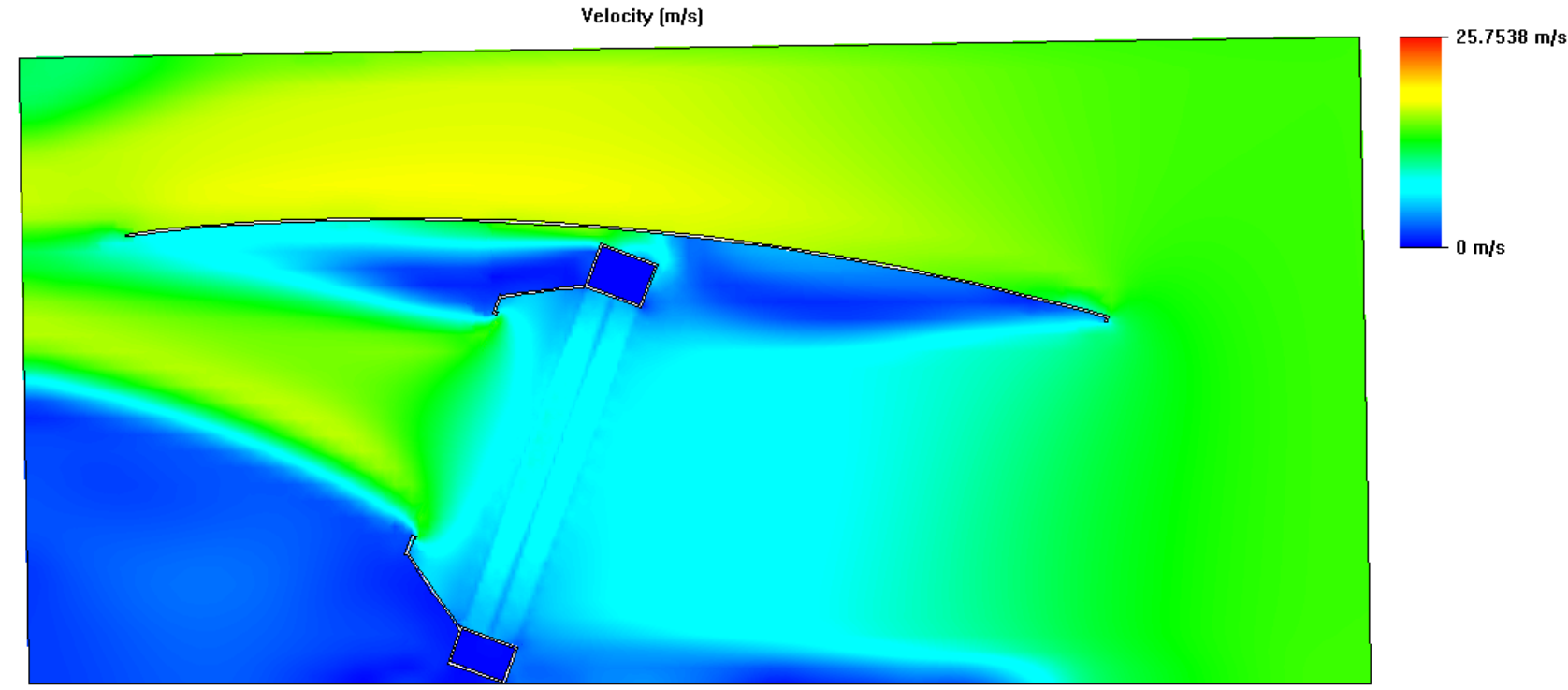

$\operatorname{Min}=0 \mathrm{~m} / \mathrm{s} \quad \operatorname{Max}=25.7538 \mathrm{~m} / \mathrm{s}$

Iteration $=\mathbf{1 9 2}$

Figure 7: Analysis of right sidepod- showing velocity plot at $14 \mathrm{~m} / \mathrm{s}$

(From Side View) 


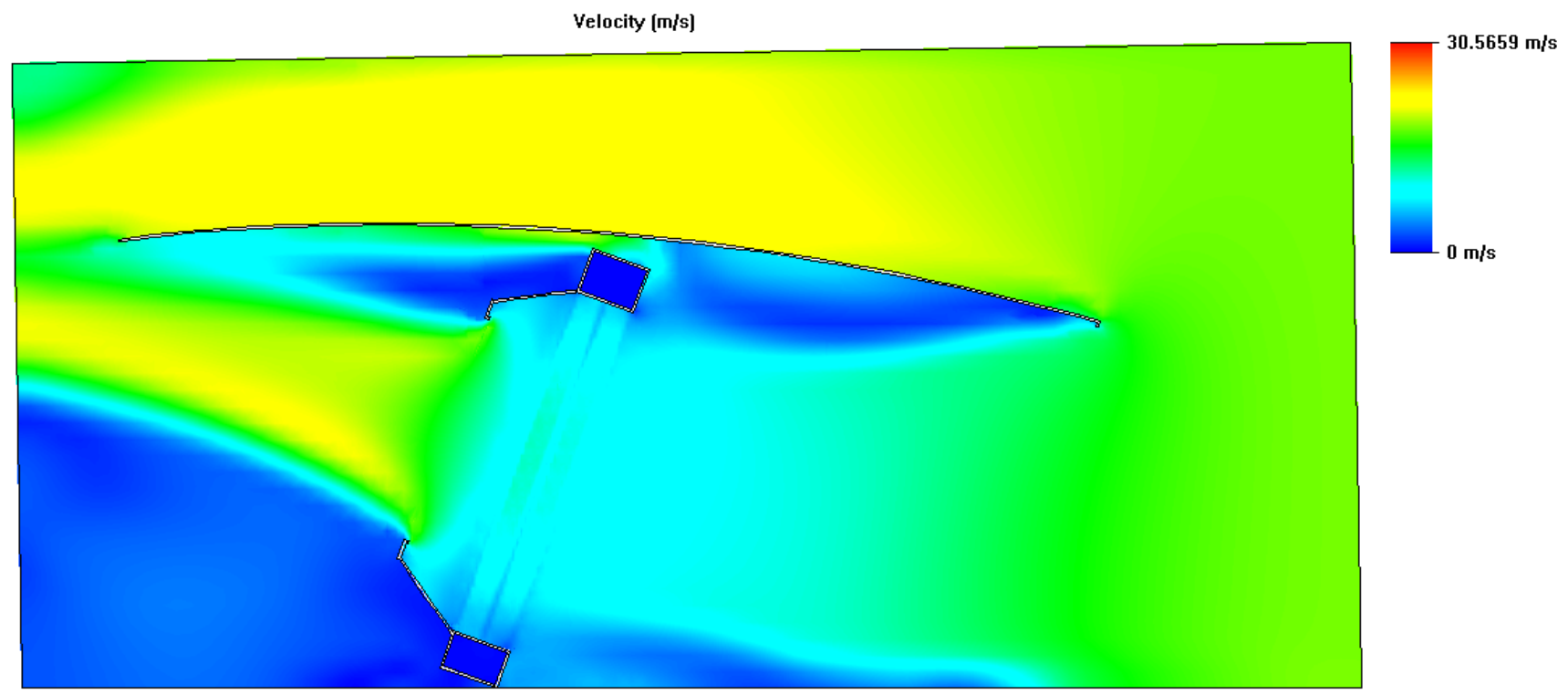

$\operatorname{Min}=0 \mathrm{~m} / \mathrm{s} \quad \operatorname{Max}=30.5659 \mathrm{~m} / \mathrm{s}$

Iteration $=\mathbf{2 2 8}$

Figure 8 : Analysis of right sidepod- velocity plot at $18 \mathrm{~m} / \mathrm{s}$

As shown in the figure there is a boundary layer seperation occuring at inner top of the sidepod. This is due to the flange which is in front of the side pod. Due to this boundary layer seperation, there is formation of turbulent eddies in that low pressure region. Also the velocity in that region is very low which will lead to high pressure and thus creating a lift instead of downforce.
The core reason of this problem was the flange. Eventhough this problem can be easily resolved by trimming down the flange, but the stiffness of the sidepod will be affected drastically. Thus a flange of $10 \mathrm{~mm}$ was kept instead of 25 $\mathrm{mm}$ with a compromise on downforce with respect to stiffness. The analysis is shown below.

Total Pressure [Pa]

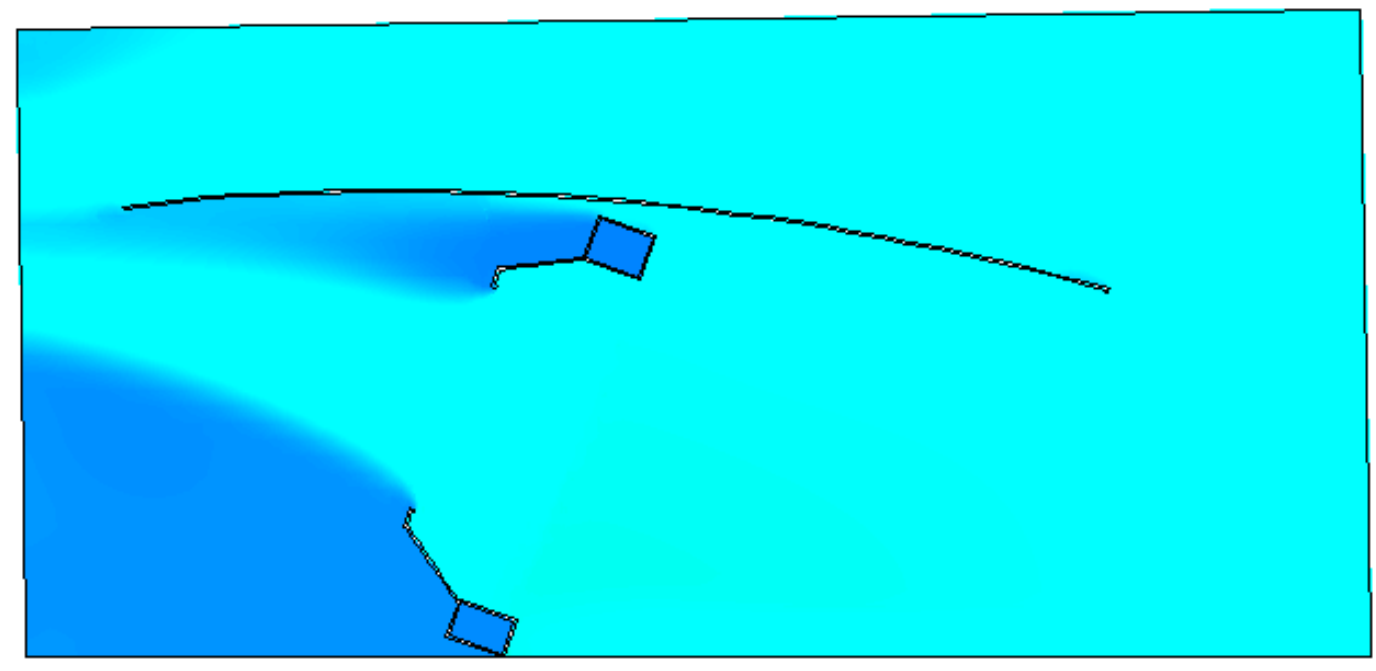

$102248 \mathrm{~Pa}$

Min=101161 Pa $\operatorname{Max}=102248 \mathrm{~Pa}$

Iteration $=192$

Figure 9: Analysis of right side pod after changes - pressure plot at $14 \mathrm{~m} / \mathrm{s}$ 
Total Pressure [Pa]

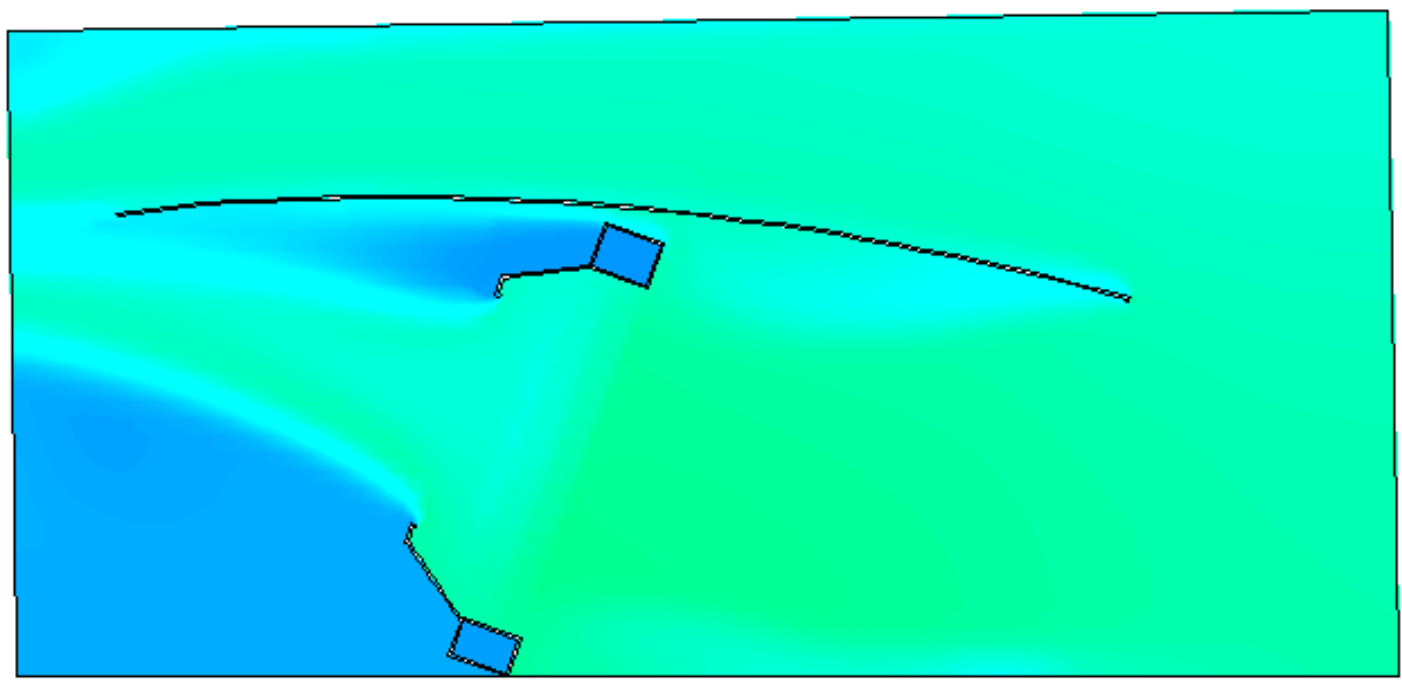

$102503 \mathrm{~Pa}$

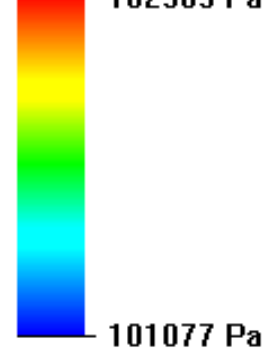

\section{Min=101077 Pa Max=102503 Pa}

Iteration $=\mathbf{2 2 9}$

Figure 10: Of right side pod after changes -pressure plot at $18 \mathrm{~m} / \mathrm{s}$

In the velocity and pressure plot for $18 \mathrm{~m} / \mathrm{s}$ the speed at radiator inlet is approx $9.5 \mathrm{~m} / \mathrm{s}$ and the pressure is atmospheric but at the outlet of the shroud the velocity is approx $18.5 \mathrm{~m} / \mathrm{s}$ and there is a vacuum pressure. Thus this design will increase the mass flow rate of air throughout the radiator helping the fluid to cool faster.

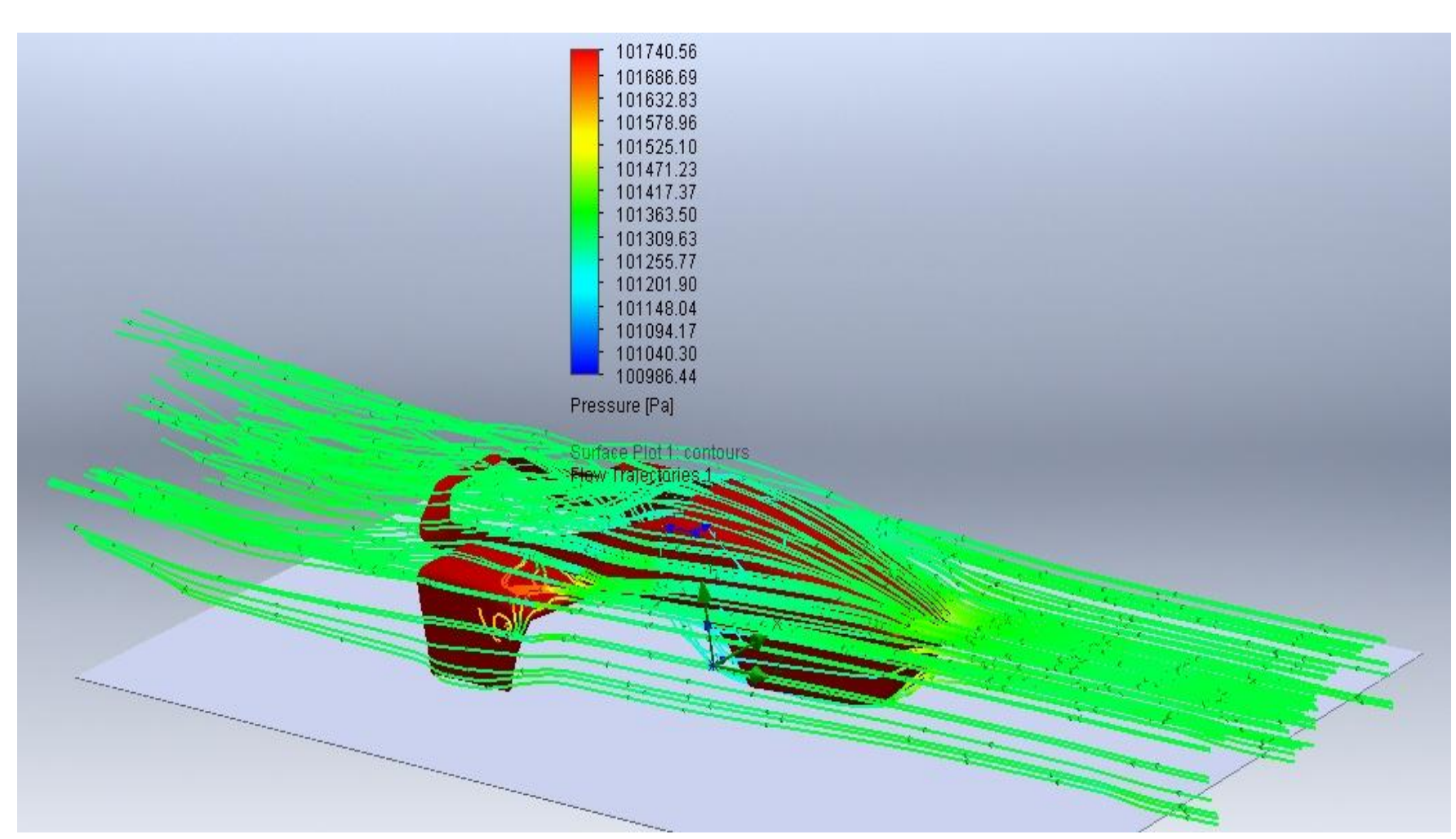

Figure 11: Flow Diagram on final iteration without complete chassis and assembly.

\section{FINAL ITERATION (ONLY BODYWORKS):}

The flow over the final iteration is shown in the picture below. The flow is almost laminar as seen in the picture. The average pressure was found to be $101309.63 \mathrm{~Pa}$ which is little less than atmospheric pressure which is $101325 \mathrm{~Pa}$. It was found that there is a drag of $-.91 \mathrm{~N}$ and down force of $-11.92 \mathrm{~N}$. Thus the objective of minimum drag was achieved by this design. 


\section{COMPLETE ANALYSIS}

The model was analysed with the boundary conditions of 18 $\mathrm{m} / \mathrm{s}$ velocity and $40 \mathrm{~mm}$ ground clearance.

Flow distribution without the assembly was totally laminar as seen in previous figures. Due to incorporation of entire assembly there are generation of turbulent flow due to various reasons such as wheels, open cockpit area, driver helmet, power train and drive train assemblies, etc. It can be seen that there is formation of wake behind the vehicle. The turbulence is created as the flow separation occurs. There is a low pressure generated inside the cockpit thus the air is forced into the cockpit leading to formation of eddies. Also the driver helmet resembles a sphere in the space.

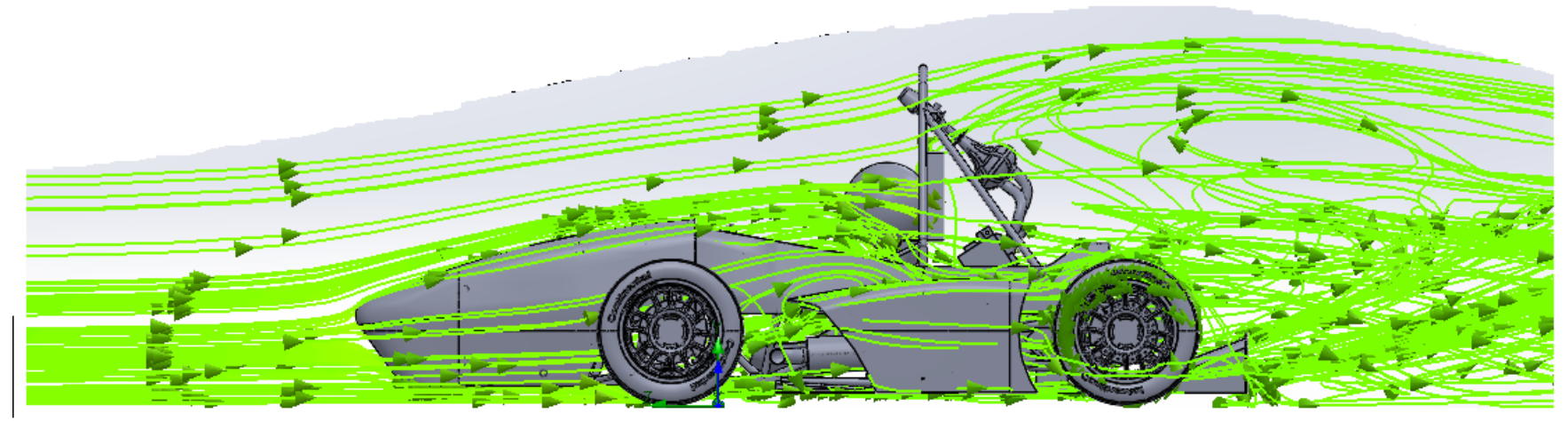

Figure12 : Flow distribution at $18 \mathrm{~m} / \mathrm{s}$ and $40 \mathrm{~mm}$ G.C.

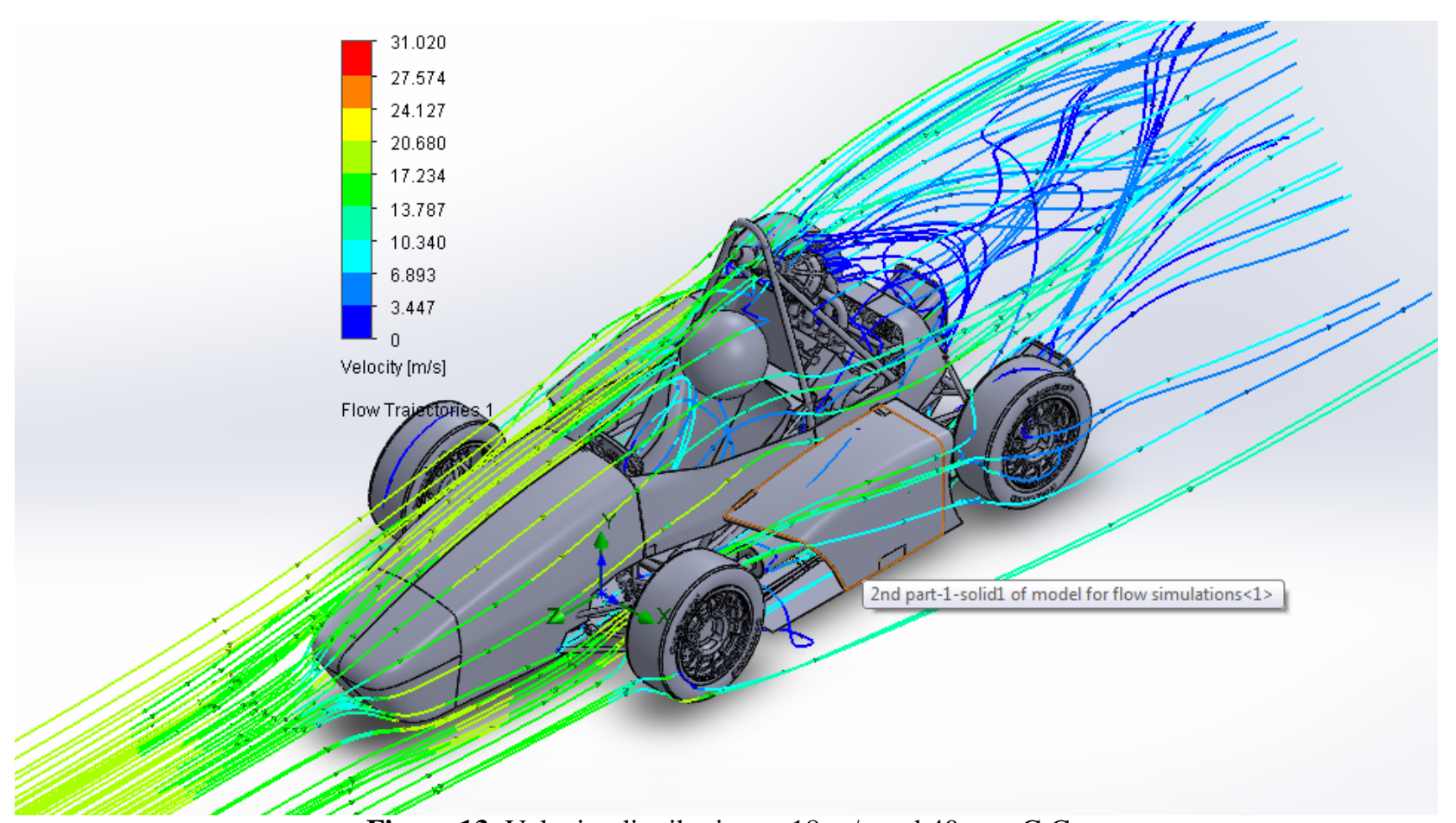

Figure 13: Velocity distribution at $18 \mathrm{~m} / \mathrm{s}$ and $40 \mathrm{~mm}$ G.C.

The velocity at inlet was $18 \mathrm{~m} / \mathrm{s}$ and ride height was $40 \mathrm{~mm}$. Velocity distribution was analysed by streamlines.

The velocity profile is shown as above. The velocity decreases slightly at the nose tip but increases while flowing over the nose. While flowing over the side pod the velocity decreases due to increase in the area. The helmet and the head restraint block the flow as a sphere and a flat plate Perpendicular to the flow. Thus there is a low velocity and high turbulent flow formed in this region. Average velocity at outlet is found to be approx $7.5 \mathrm{~m} / \mathrm{s}$. 


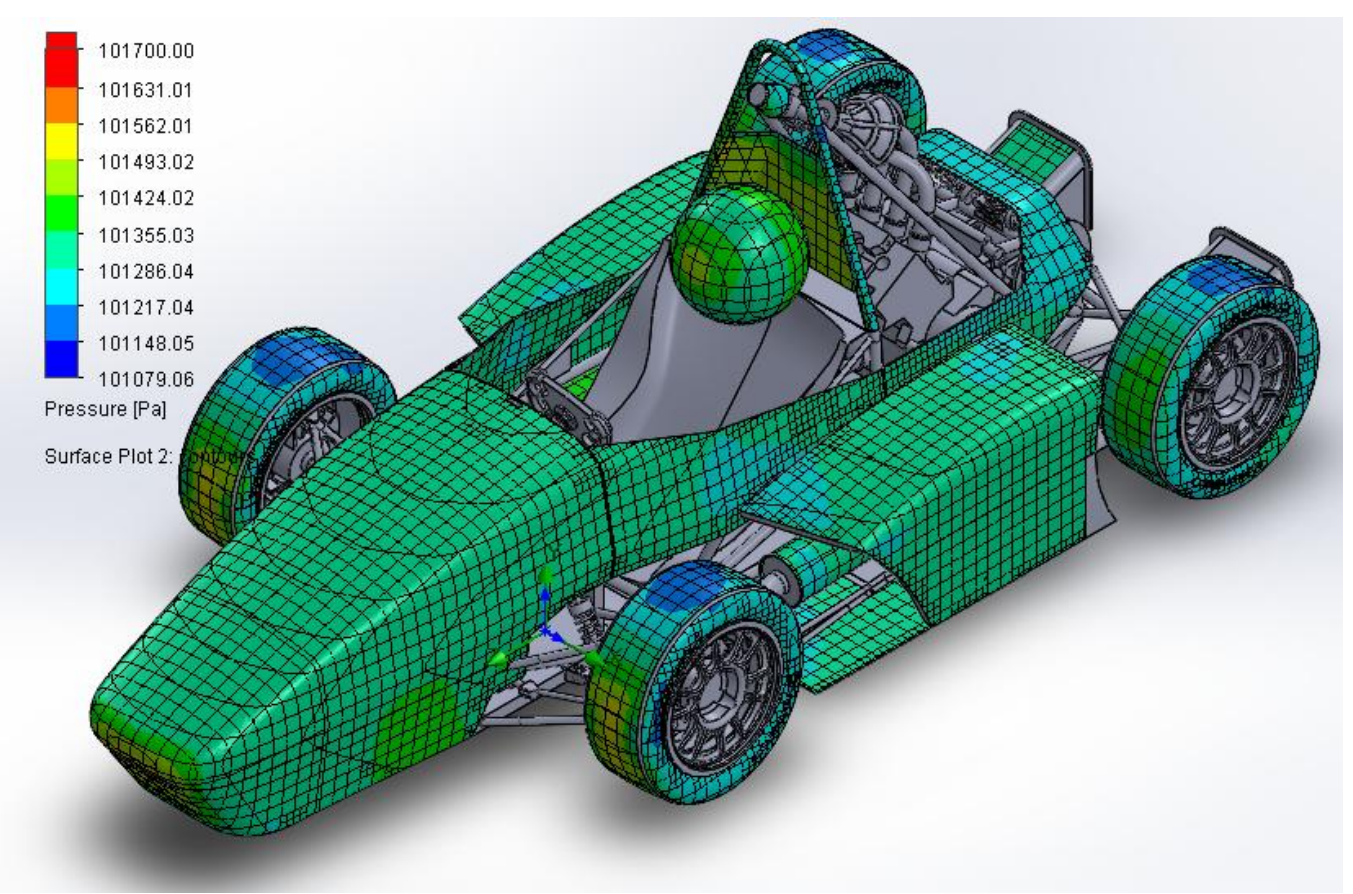

Figure 14 : Top surface pressure plot

As shown in the figure above there is approx pressure of 101286.04 $\mathrm{Pa}$ on the nose, which represent that there is slight low pressure region generated on the nose leading to some downforce. The rear panel and front of the side pods experiences a pressure of 101217.04 $\mathrm{Pa}$.

\section{Turbulence Length :}

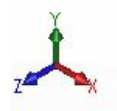

FIsometric

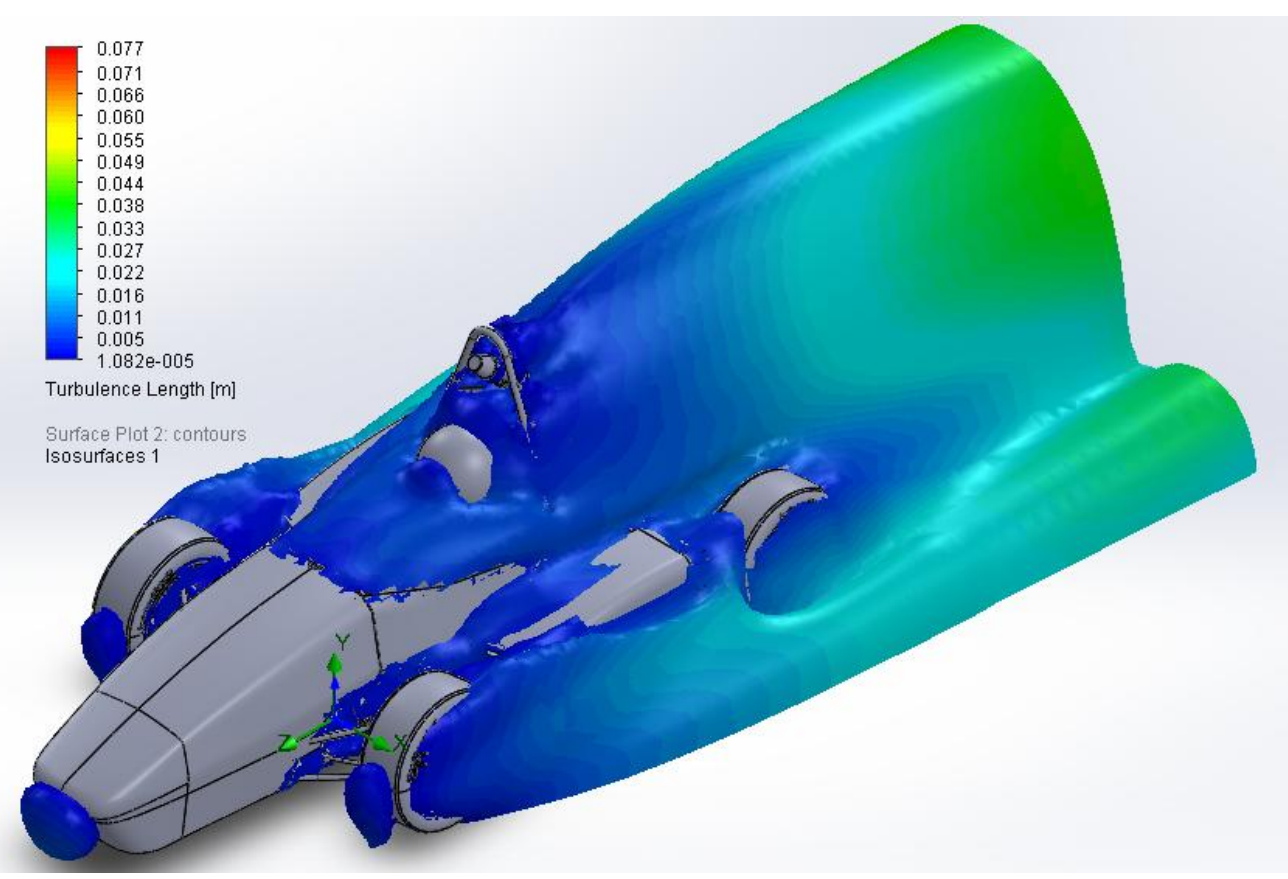

Figure 15: Turbulence Length plot at $18 \mathrm{~m} / \mathrm{s}$ and 40

Turbulence length plot represent the region in which the flow get separated and turbulence is formed, also it inform us that what is length of the turbulent air flow perpendicular to the air flow direction.

The nose section is almost laminar except the nose cone where turbulence length is of $5 \mathrm{~mm}$. In the cockpit area there is generation of turbulence due to flow separation .This turbulence length is then gradually increased across the length in the rear. Major turbulence is generated behind the head restraint. magnitude of turbulence is increases from $5 \mathrm{~mm}$ to $44 \mathrm{~mm}$. 


\section{CONCLUSION:}

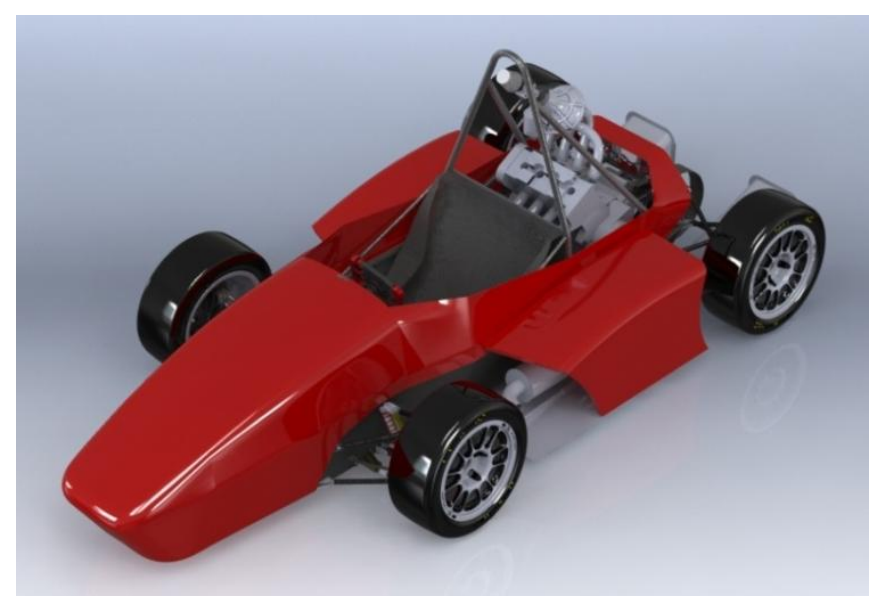

Figure 16: Final Overview of the Bodyworks

With the finalization of the designs and complete in-depth analysis, vacuum infusion of Carbon fiber would be used along with epoxy resins for manufacturing and thus aesthic bodywork with a minimum drag consideration of aerodynamics can be achieved. We obtained the downforce of $11.92 \mathrm{~N}$ and minimum drag of $-0.91 \mathrm{~N}$ drags. The body nose being a simple component would be easy to mount. Similarly side pods will be mounted from the two sides. This design will also be enriched by the use of structural foam for enhances stiffness.

\section{REFERENCES:}

[1] Anderson, J. D., Fundamentals of Aerodynamics, $4^{\text {th }}$ Edition, McGraw-Hill, San Francisco, 2007.

[2] Society of Automotive engineers tech papers of FSAE cars

[3] Jasinski, W. J., Selig, M. S., "Experimental Study of Open-Wheel Race-Car Front Wings," SAE International, Paper Number 98MSV-14.

[4] Dr. Eric Eggleston, "Sources of Energy", $2^{\text {nd }}$ Edition, 2001.

[5] R.S Khurmi, J.K Gupta, "Machine Design"

[6] K.L.Kumar, "Fluid Mechanics", $8^{\text {th }}$ Edition, 2005.

[7] S.Ramamrutham, R.Narayanan, "Strength of Materials", $6^{\text {th }}$ Edition, 2002.

[8] P.S.G, "Design data Book", $2^{\text {nd }}$ compiled Edition, 2006 